\title{
Body fat and blood pressure: comparison of blood pressure measurements in Chinese children with different body fat levels
}

\author{
Jun $\mathrm{Ma}^{1 *}$, Zhiqiang Wang ${ }^{2 *}$, Bin Dong ${ }^{1}$, Yi Song ${ }^{1}$, Peijin $\mathrm{Hu}^{1}$ and Bing Zhang ${ }^{1}$ \\ ${ }^{1}$ Institute of Child and Adolescent Health, School of Public Health, Peking University Health Sciences Center, 38 Xueyuan \\ Road, Haidian District, Beijing 100191, People's Republic of China \\ ${ }^{2}$ Centre for Chronic Disease, School of Medicine, University of Queensland, Room 817, Health Sciences Building, Royal \\ Brisbane \& Women's Hospital, Herston, QLD 4029, Australia
}

(Submitted 7 July 2011 - Final revision received 25 November 2011 - Accepted 25 November 2011 - First published online 16 January 2012)

\begin{abstract}
Children in China are experiencing a rapid increase in the prevalence of obesity, which is associated with hypertension. To compare the effect of body fat on blood pressure (BP) with that of the normal physical growth, we compared BP levels in Chinese children with different body fat levels. In the present population-based study, 13972 children in the highest-skinfold-thickness-quartile group were individually matched to 13972 children in the lowest-skinfold-thickness-quartile group by height and weight. Similarly, 5103 children in the highest-waist-circumference-quartile group were matched to the same number of children in the lowest-waist-circumference-quartile group. The high- and low-fat groups had similar height and weight but the high-fat group had significantly higher skinfold and waist circumference measurements. The differences in systolic BP (SBP) between the high- and low-skinfold-thickness groups were small: $0.01(95 \% \mathrm{CI}-0.41,0.44) \mathrm{mmHg}$ in boys and $0.20(95 \% \mathrm{CI}-0.15,0.54) \mathrm{mmHg}$ in girls. The differences in diastolic BP (DBP) were also small (0.39 and $0.38 \mathrm{mmHg}$ for boys and girls, respectively) but were statistically significant. The differences in both SBP and DBP between the high- and low-waist-circumference groups were small but not statistically significant. For a given body size as measured by height and weight, relative body fat had little impact on BP levels in these children. Fat mass and lean mass may have a similar quantitative impact on BP in healthy-weight children.
\end{abstract}

Key words: Body fat: Blood pressure: Children: Adolescents: Waist circumference: Skinfold thickness

China is experiencing a rapid increase in obesity ${ }^{(1)}$, which is associated with hypertension in children. Elevated blood pressure (BP) in childhood is a risk factor for CVD in adult life ${ }^{(2)}$. Current guidelines published in 'The fourth report on the diagnosis, evaluation, and treatment of high blood pressure in children and adolescents' provide the current BP standards in children and adolescents based on sex, age and height ${ }^{(3)}$. In growing children, separating the effect of normal physical growth on BP from that of obesity on BP values is important but challenging. A number of studies have indicated that weight is more closely correlated with $\mathrm{BP}$ levels than height ${ }^{(3-6)}$. However, weight-specific standards are not encouraged, as they are considered to obscure elevated BP resulting from obesity ${ }^{(4,7)}$. Anthropometric measurements of body fat such as waist circumference and skinfold thickness are associated with BP in children ${ }^{(8)}$. Recent studies have demonstrated that BMI is the strongest determinant of $\mathrm{BP}$ in children among body composition measurements including body fat measures using dualenergy X-ray absorptiometry ${ }^{(9,10)}$. It is clear that children with larger body sizes tend to have higher BP values. Since weight, waist circumference and BMI are crude measurements of total lean mass and fat mass values, the effect of body fat, independent of overall body size, on BP is still not clear. Lean body mass has been reported to be an independent predictor of systolic BP (SBP) in 9 year-old British children ${ }^{(9)}$. Separating the effect of fat mass from that of total body size is difficult because all fat mass measurements and overall body size measurements for population studies are strongly correlated. Understanding the effect of fat mass on BP, independent of total body size, is important for distinguishing whether a relatively high $\mathrm{BP}$ in a child is normal or pathological.

Abbreviations: BP, blood pressure; CNSSCH, Chinese National Survey on Students' Constitution and Health; DBP, diastolic blood pressure; SBP, systolic blood pressure.

*Corresponding authors: Z. Wang, fax +61733465178, email z.wang@uq.edu.au; J. Ma, fax +8610 82801178, email majunt@bjmu.edu.cn 
In the present study, we employed a matching technique to ensure that the children with high body fat to have the same distributions of height and weight as those with low body fat. Anthropometric measurements of skinfold thickness and waist circumference were used as subcutaneous and central adiposity markers, respectively. The objective of the present study was to assess the independent effect of body fat on $\mathrm{BP}$ in children with similar height and weight distributions.

\section{Methods \\ Participants}

In the 2005 Chinese National Survey on Students' Constitution and Health $(\mathrm{CNSSCH})$, data on a nationally representative sample of children aged 7-18 years were used to assess the associations between skinfold thickness and BP. The survey included over 230000 participants from 1320 primary and secondary schools in China. Based on the sum of triceps and subscapular skinfold thickness values, we divided the participants into four groups of equal size. The participants who had skinfold thickness values greater than age- and sex-specific 75th percentiles (the highest quartile) were classified as having 'high subcutaneous body fat' and those with values less than the 25th percentile (the lowest quartile) as having 'low subcutaneous body fat'. Each participant in the highest quartile group was matched to one participant in the lowest quartile group, if available, according to the following criteria: (1) with the same age, which was calculated in whole years from the date of birth, and sex, (2) from the same geographical region, (3) with an identical or a closest weight within $1 \mathrm{~kg}$ and (4) with an identical or a closest height within $1 \mathrm{~cm}$. To minimise potential selection bias due to the researcher's subjective decision on choosing matching individuals, we developed a computer program to search and match study participants. If multiple subjects with the same age, sex, weight, height and geographical region in the database were identified, only one participant was randomly selected. We individually matched 13972 pairs of children (6439 pairs of boys and 7533 pairs of girls).

To assess the association between waist circumference and BP, we used the waist circumference data collected in the 2008 Chinese National Surveillance on Students' Physical Fitness and Health. Chinese children aged 7-18 years in this survey were from fifteen Chinese provinces and autonomous regions $^{(11)}$. In this survey, waist circumference was measured in addition to the same set of anthropometric and BP measurements as those in the 2005 survey. Each child in the highestwaist-circumference-quartile group was individually matched to one in the lowest-waist-circumference-quartile group according to the same criteria as mentioned above. A total of 5103 pairs of children (2222 pairs of boys and 2881 pairs of girls) were matched.

\section{Anthropometric measurements}

In both surveys, height $(\mathrm{cm})$ and weight $(\mathrm{kg})$ were measured according to the standard procedures in all sites across the country $^{(12)}$. Subjects were required to wear only light clothes and stand straight, barefoot and at ease when being measured. Weight was measured to the nearest $0 \cdot 1 \mathrm{~kg}$ with a standardised scale and height to the nearest $0 \cdot 1 \mathrm{~cm}$ with a portable stadiometer. Both the scales and stadiometers were calibrated before use. BMI was calculated as body weight (kg) divided by height $(\mathrm{m})$ squared $\left(\mathrm{kg} / \mathrm{m}^{2}\right)$. Waist circumference was measured midway between the lowest rib and the superior border of the iliac crest at the end of normal expiration to the nearest $0 \cdot 1 \mathrm{~cm}$. Waist circumference data were only available in the 2008 survey. Skinfold thickness was measured in the 2005 survey using skinfold calipers (Minjia, GMCS-PZQ; Beijing Xindong Huateng Sports Instruments Company, Limited) to the nearest $0.5 \mathrm{~mm}$ at two sites on the right side of the body: (1) triceps, between the tip of the olecranon process of the ulna and the acromion process of the scapula, and (2) subscapular, $1.0 \mathrm{~cm}$ below the tip of the scapula. In each participant, three measurements were taken and the middle value was recorded for one skinfold site. The sum of triceps and subscapular skinfolds was used to classify participants into different body subcutaneous fat groups. All measurements were conducted by a team of field technicians in each administrative district, and those technicians were required to pass a training course for weight, height, waist circumference, skinfold thickness and BP measurements.

\section{Blood pressure measurements}

All $\mathrm{BP}$ readings were obtained at a single examination visit according to a standard protocol. As recommended by the National High Blood Pressure Education Program Working Group on High Blood Pressure in Children and Adolescents ${ }^{(3)}$, $\mathrm{BP}$ readings of the right arm by an auscultation method with a standardised clinical sphygmomanometer were used in the present study. A stethoscope was placed over the brachial artery pulse, proximal and medial to the cubital fossa and below the bottom edge of the cuff. Cuff bladders with different sizes $(7,9$ and $12 \mathrm{~cm}$ ) for children were available in the survey site. An appropriate cuff bladder width covering the one-half to three-quarter of the upper arm length was chosen. The participants were asked to rest in the sitting position for $10-15 \mathrm{~min}$ before the measurement. SBP was determined by the onset of the 'tapping' Korotkoff sounds (K1) and diastolic BP (DBP) as the fifth Korotkoff sound (K5) or the disappearance of the Korotkoff sounds.

\section{Statistical analysis}

To assess the success of matching, we compared the lowestbody-fat-quartile group with the highest quartile group by age, height, weight and BMI using a paired $t$ test. Means and standard deviations of height, weight, BMI, waist circumference and skinfold thickness measurements for each body fat group were calculated separately for boys and girls. Observed height and weight values were converted into $z$-scores according to the WHO growth reference 2007 for school-age children and adolescents (http://www.who.int/growthref/en/). 
Table 1. Characteristics of the study participants according to skinfold thickness levels

(Mean values, standard deviations, number of children and percentages)

\begin{tabular}{|c|c|c|c|c|c|}
\hline & \multicolumn{4}{|c|}{ Skinfold thickness level } & \multirow[b]{3}{*}{$P$} \\
\hline & \multicolumn{2}{|c|}{$\begin{array}{l}\text { Lowest } \\
\text { quartile }\end{array}$} & \multicolumn{2}{|c|}{$\begin{array}{l}\text { Highest } \\
\text { quartile }\end{array}$} & \\
\hline & Mean & SD & Mean & SD & \\
\hline \multicolumn{6}{|l|}{ Boys } \\
\hline No. of pairs & \multicolumn{2}{|c|}{6439} & \multicolumn{2}{|c|}{6439} & \\
\hline Age (years) & $12 \cdot 9$ & 3.6 & $12 \cdot 9$ & $3 \cdot 6$ & 1 \\
\hline Weight (kg) & 43.9 & $13 \cdot 7$ & $44 \cdot 0$ & $13 \cdot 7$ & 0.69 \\
\hline Weight $z$-score* & -0.1 & 0.8 & -0.1 & 0.8 & $0 \cdot 12$ \\
\hline Height $(\mathrm{cm})$ & $153 \cdot 4$ & $18 \cdot 0$ & $153 \cdot 3$ & $18 \cdot 0$ & 0.87 \\
\hline Height $z$-score & -0.4 & 0.9 & -0.4 & 0.9 & 0.63 \\
\hline $\mathrm{BMI}\left(\mathrm{kg} / \mathrm{cm}^{2}\right)$ & $18 \cdot 1$ & $2 \cdot 2$ & $18 \cdot 1$ & $2 \cdot 2$ & $0 \cdot 12$ \\
\hline Overweight or obesity & & & & & 0.37 \\
\hline$n$ & \multicolumn{2}{|c|}{223} & \multicolumn{2}{|c|}{242} & \\
\hline$\%$ & \multicolumn{2}{|c|}{3.5} & \multicolumn{2}{|c|}{$3 \cdot 8$} & \\
\hline \multicolumn{6}{|l|}{ Skinfold thickness (mm) } \\
\hline Triceps & $5 \cdot 6$ & 1.8 & $16 \cdot 0$ & $6 \cdot 4$ & $<0.001$ \\
\hline Subscapular & $5 \cdot 7$ & 1.9 & $12 \cdot 6$ & $5 \cdot 5$ & $<0.001$ \\
\hline $\begin{array}{l}\text { Sum of triceps and } \\
\text { subscapular }\end{array}$ & 11.4 & $3 \cdot 0$ & $28 \cdot 6$ & $9 \cdot 8$ & $<0.001$ \\
\hline $\mathrm{SBP}(\mathrm{mmHg})$ & 104.5 & $12 \cdot 7$ & 104.5 & $12 \cdot 0$ & 0.95 \\
\hline DBP (mmHg) & $64 \cdot 2$ & $10 \cdot 3$ & $64 \cdot 6$ & $9 \cdot 7$ & 0.025 \\
\hline \multicolumn{6}{|l|}{ Girls } \\
\hline No. of pairs & \multicolumn{2}{|c|}{7533} & \multicolumn{2}{|c|}{7533} & \\
\hline Age (years) & $12 \cdot 8$ & 3.6 & $12 \cdot 8$ & $3 \cdot 6$ & 1 \\
\hline Weight (kg) & $40 \cdot 3$ & $11 \cdot 3$ & $40 \cdot 4$ & $11 \cdot 3$ & 0.58 \\
\hline Weight $z$-score* & -0.4 & 0.7 & -0.3 & 0.7 & 0.08 \\
\hline Height $(\mathrm{cm})$ & $147 \cdot 8$ & $14 \cdot 2$ & $147 \cdot 7$ & $14 \cdot 2$ & 0.79 \\
\hline Height $z$-score & -0.5 & 0.9 & -0.5 & 0.9 & 0.52 \\
\hline $\mathrm{BMI}\left(\mathrm{kg} / \mathrm{cm}^{2}\right)$ & $18 \cdot 0$ & $2 \cdot 4$ & $18 \cdot 0$ & $2 \cdot 4$ & 0.09 \\
\hline Overweight or obesity & & & & & 0.89 \\
\hline$n$ & \multicolumn{2}{|c|}{97} & \multicolumn{2}{|c|}{99} & \\
\hline$\%$ & \multicolumn{2}{|c|}{1.3} & \multicolumn{2}{|c|}{$1 \cdot 3$} & \\
\hline \multicolumn{6}{|l|}{ Skinfold thickness (mm) } \\
\hline Triceps & $9 \cdot 3$ & $3 \cdot 3$ & $19 \cdot 4$ & $6 \cdot 3$ & $<0.001$ \\
\hline Subscapular & $8 \cdot 1$ & $3 \cdot 4$ & $16 \cdot 6$ & $6 \cdot 8$ & $<0.001$ \\
\hline $\begin{array}{l}\text { Sum of triceps and } \\
\text { subscapular }\end{array}$ & $17 \cdot 4$ & $6 \cdot 1$ & $36 \cdot 0$ & $11 \cdot 6$ & $<0.001$ \\
\hline $\mathrm{SBP}(\mathrm{mmHg})$ & $100 \cdot 7$ & $11 \cdot 0$ & $100 \cdot 9$ & $10 \cdot 7$ & 0.28 \\
\hline $\mathrm{DBP}(\mathrm{mmHg})$ & $63 \cdot 1$ & 9.7 & 63.5 & $9 \cdot 1$ & 0.013 \\
\hline
\end{tabular}

SBP, systolic blood pressure; DBP, diastolic blood pressure.

* Weight $z$-scores were calculated for children under 10 years of age for which the 2007 WHO reference data were available.

Overweight was defined as a BMI above $1 \mathrm{SD}$ and obesity as above $2 \mathrm{SD}$ of the WHO reference ${ }^{(13)}$. Age- and sex-specific SBP and DBP mean values were calculated and compared between the two groups. Mean differences between the highand low-body-fat groups and their 95\% CI were calculated and tested using a paired $t$ test. Potential residual confounding effects of body size measurements were further adjusted for using a multiple linear regression. The nature of the matched data was taken into consideration by specifying the matched pairs as clusters to obtain the robust estimate of variance. All analyses were conducted using Stata $11^{(14)}$. The present study was conducted according to the guidelines laid down in the Declaration of Helsinki and was approved by the Medical Research Ethics Committee of the University of Queensland (\#2011001199).

\section{Results}

Table 1 shows some characteristics of the study participants stratified by skinfold thickness levels. According to our matching criteria, the highest- and the lowest-skinfold-thicknessquartile groups had the same age within each pair. The two groups had similar weight, height and BMI values, but the skinfold thickness measures in the highest quartile group were substantially and significantly higher than the corresponding values in the lowest quartile group, as expected according to the nature of the design. Differences in the sum of triceps and subscapular skinfolds were as high as $17.2 \mathrm{~mm}$ (28.8 mm compared with $10.6 \mathrm{~mm}$ ) for boys and $18.6 \mathrm{~mm}$ (36.0 mm compared with $17.4 \mathrm{~mm}$ ) for girls.

Similarly, Table 2 shows the characteristics of the study participants stratified by waist circumference levels. The highest- and the lowest-waist-circumference-quartile groups had similar age, height, weight and BMI values, but the two groups were substantially and significantly different in waist circumference. Waist circumference levels in the highest quartile group were 13.7 and $12.2 \mathrm{~cm}$ higher than those in the lowest quartile group for boys and girls, respectively.

Table 2. Characteristics of the study participants according to waist circumference levels, matched by age, sex, weight and height

(Mean values, standard deviations, number of children and percentages)

\begin{tabular}{|c|c|c|c|c|c|}
\hline & \multicolumn{4}{|c|}{ Waist circumference level } & \multirow[b]{3}{*}{$P$} \\
\hline & \multicolumn{2}{|c|}{$\begin{array}{l}\text { Lowest } \\
\text { quartile }\end{array}$} & \multicolumn{2}{|c|}{$\begin{array}{l}\text { Highest } \\
\text { quartile }\end{array}$} & \\
\hline & Mean & SD & Mean & SD & \\
\hline \multicolumn{6}{|l|}{ Boys } \\
\hline No. of pairs & \multicolumn{2}{|c|}{2222} & \multicolumn{2}{|c|}{2222} & \\
\hline Age (years) & $12 \cdot 7$ & 3.7 & $12 \cdot 7$ & 3.6 & 1 \\
\hline Weight (kg) & 44.6 & $15 \cdot 0$ & 44.8 & $15 \cdot 0$ & 0.66 \\
\hline Weight $z$-score* & -0.1 & 0.9 & 0 & 0.9 & 0.17 \\
\hline Height $(\mathrm{cm})$ & $153 \cdot 0$ & $18 \cdot 4$ & $153 \cdot 3$ & $18 \cdot 4$ & 0.90 \\
\hline Height $z$-score & -0.3 & 0.9 & -0.3 & 0.9 & 0.73 \\
\hline $\mathrm{BMI}\left(\mathrm{kg} / \mathrm{cm}^{2}\right)$ & $18 \cdot 4$ & 2.9 & 18.5 & 2.9 & 0.21 \\
\hline Overweight or obese & & & & & 0.35 \\
\hline$n$ & \multicolumn{2}{|c|}{222} & \multicolumn{2}{|c|}{241} & \\
\hline$\%$ & \multicolumn{2}{|c|}{$10 \cdot 0$} & \multicolumn{2}{|c|}{$10 \cdot 9$} & \\
\hline Waist circumference $(\mathrm{cm})$ & $58 \cdot 6$ & $6 \cdot 1$ & $72 \cdot 3$ & $7 \cdot 6$ & $<0.001$ \\
\hline $\mathrm{SBP}(\mathrm{mmHg})$ & 104.9 & $12 \cdot 9$ & 105.4 & $13 \cdot 7$ & 0.21 \\
\hline $\mathrm{DBP}(\mathrm{mmHg})$ & $66 \cdot 3$ & 9.5 & $66 \cdot 3$ & $9 \cdot 8$ & 0.93 \\
\hline \multicolumn{6}{|l|}{ Girls } \\
\hline No. of pairs & \multicolumn{2}{|c|}{2881} & \multicolumn{2}{|c|}{2881} & \\
\hline Age (years) & $12 \cdot 6$ & 3.7 & $12 \cdot 6$ & 3.7 & 1 \\
\hline Weight (kg) & 40.5 & 11.9 & $40 \cdot 8$ & $11 \cdot 8$ & 0.36 \\
\hline Weight $z$-score* & -0.2 & 0.7 & -0.1 & 0.7 & 0.013 \\
\hline Height $(\mathrm{cm})$ & 147.4 & $14 \cdot 2$ & $147 \cdot 3$ & $14 \cdot 2$ & 0.80 \\
\hline Height $z$-score & -0.4 & 0.9 & -0.4 & 0.9 & 0.53 \\
\hline BMI $\left(\mathrm{kg} / \mathrm{cm}^{2}\right)$ & $18 \cdot 2$ & $2 \cdot 8$ & $18 \cdot 3$ & $2 \cdot 8$ & 0.17 \\
\hline Overweight or obese & \multirow{2}{*}{\multicolumn{2}{|c|}{150}} & & & 0.55 \\
\hline$n$ & & & \multicolumn{2}{|c|}{140} & \\
\hline$\%$ & \multicolumn{2}{|c|}{$5 \cdot 2$} & \multicolumn{2}{|c|}{4.9} & \\
\hline Waist circumference $(\mathrm{cm})$ & $56 \cdot 7$ & 5.7 & 68.9 & 7.3 & $<0.001$ \\
\hline $\mathrm{SBP}(\mathrm{mmHg})$ & 101.9 & 11.5 & $101 \cdot 8$ & $11 \cdot 3$ & 0.70 \\
\hline $\mathrm{DBP}(\mathrm{mmHg})$ & 64.9 & 8.9 & 64.6 & $9 \cdot 0$ & 0.24 \\
\hline
\end{tabular}

SBP, systolic blood pressure; DBP, diastolic blood pressure.

* Weight $z$-scores were calculated for children under 10 years of age for which the 2007 WHO reference data were available. 
(a)

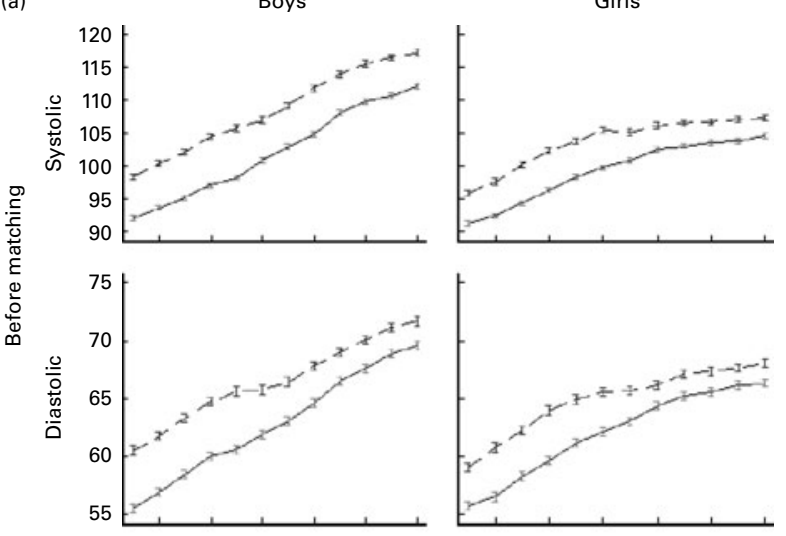

(b)

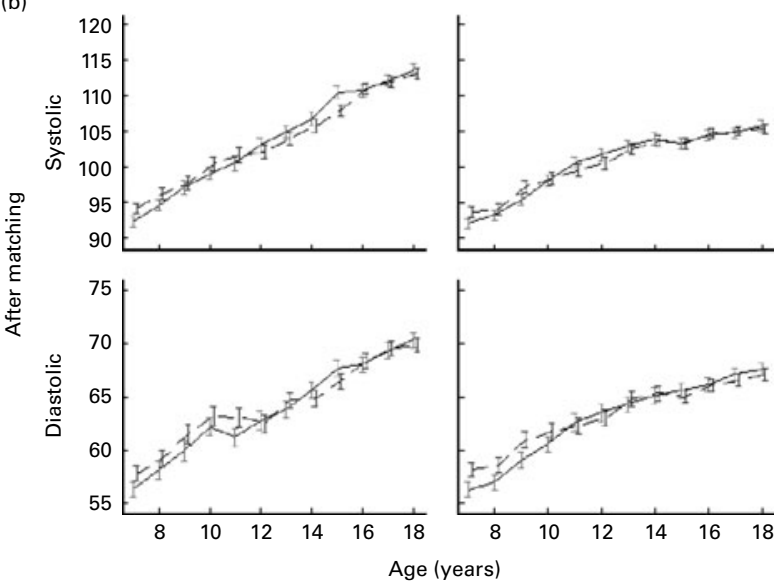

Fig. 1. Systolic and diastolic blood pressure values $(\mathrm{mmHg})$ for Chinese children with different skinfold thickness levels (a) before and (b) after matching by age, sex, height, weight and place of residence. Values are means, with $95 \% \mathrm{Cl}$ represented by vertical bars. —, Low; --, high.

$Z$-scores for height and weight were lower than zero, indicating that our study participants were shorter and lighter than the children of the WHO reference population. The prevalence of overweight and obesity according to BMI values was low and similar in the different body fat groups (Tables 1 and 2).

We calculated age- and sex-specific SBP and DBP values in the highest- and the lowest-skinfold-thickness-quartile groups before and after matching by age, sex, weight, height and geographical region. Before matching, the highest-skinfold-thickness-quartile group had significantly and consistently higher SBP and DBP values than the lowest-skinfold-thickness-quartile group in all ages and sexes (Fig. 1(a)). On average, SBP was $6.5(95 \%$ CI $6.3,6.7) \mathrm{mmHg}$ higher for boys and 4.5 (95\% CI 4.4, 4.7) $\mathrm{mmHg}$ higher for girls in the highest-skinfold-thickness-quartile group than in the lowest quartile group. The difference in DBP between the highest- and lowest-skinfold-thickness-quartile groups was 3.7 (95 CI 3.6, $3.9) \mathrm{mmHg}$ for boys and 2.9 (95\% CI $2 \cdot 8,3.1) \mathrm{mmHg}$ for girls. After matching the highest- and lowest-skinfoldthickness-quartile groups by age, sex, height, weight and geographical region, the differences in BP between the two

groups diminished in all age and sex groups (Fig. 1(b)). The average differences in SBP between the two groups were $0.01(95 \% \mathrm{CI}-0.41,0 \cdot 11) \mathrm{mmHg}$ for boys and 0.20 (95\% CI $-0 \cdot 15,0.54)$ for girls, and these differences were not statistically significant. The differences in DBP were also substantially reduced (boys: $0.39 \mathrm{mmHg}, 95 \% \mathrm{CI} 0.05,0.74 \mathrm{mmHg}$, $P=0.025$; girls: $0.38 \mathrm{mmHg}, \quad 95 \%$ CI $0.08, \quad 0.68 \mathrm{mmHg}$, $P=0 \cdot 013)$.

Before matching by age, sex, height, weight and geographical region, children in the highest-waist-circumferencequartile group had significantly higher BP levels than those in the lowest quartile group in all age and sex groups (Fig. 2(a)). After matching, the differences in both SBP and DBP between the two groups were substantially reduced, and these differences were not statistically significant (Fig. 2(b)). The differences in SBP between the highest- and lowest-waist-circumference-quartile groups were only 0.50 $(95 \% \mathrm{CI}-0.28,1.3) \mathrm{mmHg}$ for boys and $-0.12(95 \% \mathrm{CI}$ $-0.70,0.47) \mathrm{mmHg}$ for girls; and the differences in DBP were $-0.03(95 \% \mathrm{CI}-0.59,0.54) \mathrm{mmHg}$ for boys and $-0.28(95 \% \mathrm{CI}-0.73,0 \cdot 19) \mathrm{mmHg}$ for girls.

(a)
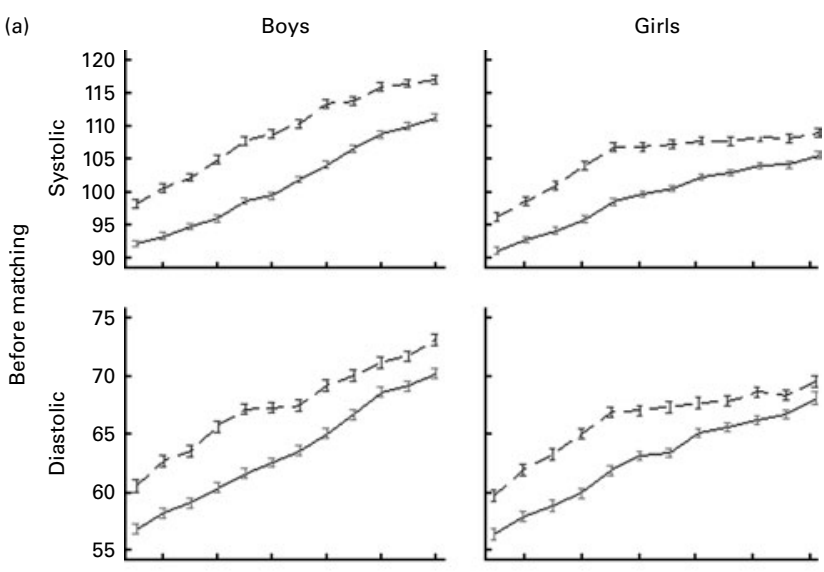

(b)
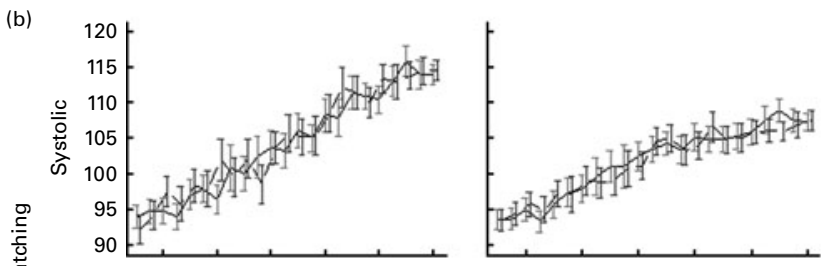

$$
\text { 高 }
$$
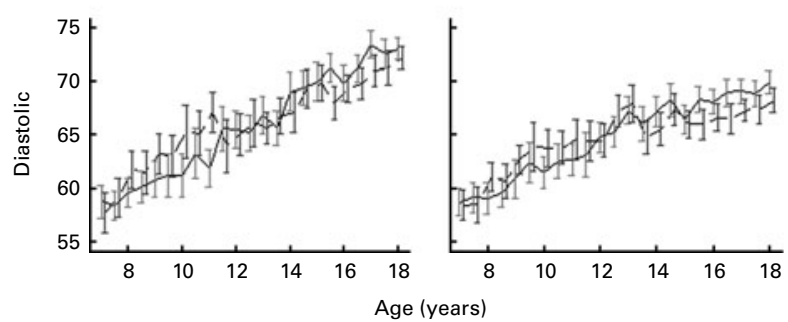

Fig. 2. Systolic and diastolic blood pressure values $(\mathrm{mmHg})$ for Chinese children with different waist circumference levels (a) before and (b) after matching by age, sex, height, weight and place of residence. Values are means, with $95 \% \mathrm{Cl}$ represented by vertical bars. _-, Low; --, high. 


\section{Discussion}

Using two nationally representative samples, we assessed the effect of relative body fat on BP levels in children. By employing a matching technique, we found that SBP levels of two groups of children with similar height and weight distributions but with significantly different skinfold thickness levels were similar. Although the differences in DBP levels were statistically significant, the absolute differences between the highand low-skinfold-thickness groups were very small, less than $0.4 \mathrm{mmHg}$.

Waist circumference is a marker of central adiposity. For two children with the same height and weight, the one with a higher waist circumference indicates a higher level of central adiposity. Although waist circumference levels in the two groups differed by as much as $12 \mathrm{~cm}$ in the present study, once body height and weight were taken into consideration, children with high waist circumference had similar BP levels to those with low waist circumference. The present findings imply that BP levels are driven by overall body size, and fat mass may have similar impact on BP levels as the same amount of lean body mass.

It has been established that BP and body size or adiposity measurements are positively correlated ${ }^{(3,4,6,9,10,15-28)}$. Recent studies have shown that BMI, a measurement encompassing both fat and lean mass, is a better predictor of BP than the adiposity measure using dual-energy X-ray absorptiometry ${ }^{(9,10)}$. Our previous study in Chinese children demonstrates that weight is a better predictor of $\mathrm{BP}$ than $\mathrm{BMI}^{(29)}$. It appears that the measures representing overall body size predict $\mathrm{BP}$ better than do the measures representing body fat alone.

The current BP reference percentile values have been constructed as a function of height rather than a function of weight or $\mathrm{BMI}^{(3-5)}$. It is considered that normal $\mathrm{BP}$ reference percentiles should not be constructed as a function of weight because weight-based BP reference values would obscure elevated $\mathrm{BP}$ resulting from overweight or obesity ${ }^{(3-5)}$. As demonstrated in the present study, regardless of the level of relative body fat, BP is influenced by overall body size. In other words, the association of overall body size with BP is beyond the association between body fat and BP. Therefore, lean mass plays a similar and an important role in determining BP levels in children. A previous study has demonstrated that lean body mass is a more important correlate of the haemodynamic determinants of BP than is fat mass in children and adolescents ${ }^{(30)}$. Several possible mechanisms of the associations between lean mass and BP have been postulated such as muscle pressor reflexes, muscle composition and growth factors $^{(31)}$. Even though the mechanisms are not clear, the distinction of elevated $\mathrm{BP}$ related to increased fat mass and that related to increased lean mass may have public health and clinical relevance.

The present findings imply that children with a large athletic build are expected to have similar BP levels as obese children with similar height and weight. However, the elevated BP, as determined according to the current normal cut-off values for children with an athletic build, is mainly associated with an increased lean (or non-fat) mass. Further research is needed to investigate whether high BP associated with an increased lean mass should be considered pathological. BP is an endpoint measure of cardiovascular adaptation, and this relationship is likely to become maladaptive with obesity. A high BP associated with an increased fat mass and that associated with an increased lean mass may have different health effects on children. A distinction between the two types of high BP may be useful for choosing appropriate interventions. Further follow-up studies are needed to investigate whether elevated BP related to increased lean body mass has different associations with future cardiovascular outcomes from those for elevated BP related to increased fat mass.

There are several strengths in the present study. The data were derived from two large nationally representative samples in China. Using a matching technique, we made the two groups strictly comparable at the design stage in terms of their overall body size as measured by height and weight. By comparing two extreme body fat groups with over $17 \mathrm{~mm}$ difference in skinfold thickness, if there is a true association between skinfold thickness and BP, independent of body size, it is likely to be detected in the present study. The study participants were aged between 7 and 18 years, and, therefore, the present findings are obtained from and applicable to a wider age range than previous studies ${ }^{(9,10)}$. Due to the nature of matching, obese individuals with extremely high weight (or BMI) in the population were likely to be excluded from the present study because of the lack of corresponding individuals to match. The high- and low-fat groups had similar prevalence of overweight and obesity as measured by BMI because the two groups were matched by weight and height. Therefore, the high-fat group was not more overweight as measured by BMI than the low-fat group. Our conclusion that fat mass and lean mass have similar quantitative impact on BP may only apply to healthy-weight children. Another weakness is that we used the sum of two skinfold thickness and waist circumference measures as surrogates of body fat rather than a direct adiposity measure. Within each matched pair in the present study, two children had similar height and weight but largely different levels of skinfold thickness or waist circumference. A child who had a high level of skinfold thickness or waist circumference was considered as having a higher proportion of body fat because height and weight were fixed within each pair. Even though skinfold thickness is correlated well with total body fat ${ }^{(32)}$, further studies using more accurate fat measurements are encouraged.

In conclusion, in the present study, we found that total body size determines BP levels in children. As the same amount of increment in lean mass is associated with a similar magnitude of BP elevation as that in fat mass in healthyweight children, further research is needed to assess whether the two types of elevated BP represent different risks for CVD.

\section{Acknowledgements}

The data analysis of the present study was supported by a grant from the National Health and Medical Research Council of Australia (NHMRC, 511013) to Z. W. The authors thank W. K. Liao, W. H. Xing, X. Zhang and the members of the CNSSCH 
for providing access to the survey data. J. M. and Z. W. conceived and designed the study and prepared the first draft of the manuscript. J. M., B. D., Y. S., P. H. and B. Z. conducted the research and collected the data. Z. W. developed the computer program for matching and performed the data analysis. All authors read and approved the final manuscript. There are no conflicts of interest.

\section{References}

1. Wu Y (2006) Overweight and obesity in China. BMJ 333, $362-363$.

2. Raitakari OT, Juonala M, Kahonen M, et al. (2003) Cardiovascular risk factors in childhood and carotid artery intimamedia thickness in adulthood: the Cardiovascular Risk in Young Finns Study. JAMA 290, 2277-2283.

3. National High Blood Pressure Education Program Working Group on High Blood Pressure in Children and Adolescents (2004) The fourth report on the diagnosis, evaluation, and treatment of high blood pressure in children and adolescents. Pediatrics 114, 555-576.

4. Rosner B, Cook N, Portman R, et al. (2008) Determination of blood pressure percentiles in normal-weight children: some methodological issues. Am J Epidemiol 167, 653-666.

5. Lauer RM, Burns TL \& Clarke WR (1985) Assessing children's blood pressure - considerations of age and body size: the Muscatine Study. Pediatrics 75, 1081-1090.

6. Park MK, Menard SW \& Schoolfield J (2005) Oscillometric blood pressure standards for children. Pediatr Cardiol 26, 601-607.

7. Rosner B, Prineas RJ, Loggie JM, et al. (1993) Blood pressure nomograms for children and adolescents, by height, sex, and age, in the United States. J Pediatr 123, 871-886.

8. Ruiz JR, Ortega FB, Loit HM, et al. (2007) Body fat is associated with blood pressure in school-aged girls with low cardiorespiratory fitness: the European Youth Heart Study. J Hypertens 25, 2027-2034.

9. Brion MA, Ness AR, Davey Smith G, et al. (2007) Association between body composition and blood pressure in a contemporary cohort of 9-year-old children. J Hum Hypertens 21, 283-290.

10. Wang H, Necheles J, Carnethon M, et al. (2008) Adiposity measures and blood pressure in Chinese children and adolescents. Arch Dis Child 93, 738-744.

11. Ji CY, Yt Sung R, Ma GS, et al. (2010) Waist circumference distribution of Chinese school-age children and adolescents. Biomed Environ Sci 23, 12-20.

12. Cameron N (1978) The methods of axiological anthropometry. In Human Growth [FT Falkner and JM Tanner, editors]. New York: Plenum Press.

13. de Onis M \& Lobstein T (2010) Defining obesity risk status in the general childhood population: which cut-offs should we use? Int J Pediatr Obes 5, 458-460.

14. Stata Statistical Software (2009) Release 11 [program]. College Station, TX: StataCorp LP.

15. Jones DW, Kim JS, Andrew ME, et al. (1994) Body mass index and blood pressure in Korean men and women: the Korean National Blood Pressure Survey. J Hypertens 12, $1433-1437$.
16. Rosner B, Cook N, Portman R, et al. (2009) Blood pressure differences by ethnic group among United States children and adolescents. Hypertension 54, 502-508.

17. McGavock JM, Torrance B, McGuire KA, et al. (2007) The relationship between weight gain and blood pressure in children and adolescents. Am J Hypertens 20, 1038-1044.

18. Torrance B, McGuire KA, Lewanczuk R, et al. (2007) Overweight, physical activity and high blood pressure in children: a review of the literature. Vasc Health Risk Manag 3, 139-149.

19. Barba G, Casullo C, Dello Russo M, et al. (2008) Gender-related differences in the relationships between blood pressure, age, and body size in prepubertal children. Am J Hypertens 21, 1007-1010.

20. Barba G, Troiano E, Russo P, et al. (2006) Body mass, fat distribution and blood pressure in Southern Italian children: results of the ARCA project. Nutr Metab Cardiovasc Dis 16, $239-248$.

21. Taksande A, Chaturvedi P, Vilhekar K, et al. (2008) Distribution of blood pressure in school going children in rural area of Wardha distric, Maharashtra, Indiat. Ann Pediatr Cardiol 1, 101-106.

22. Ataei N, Hosseini M \& Iranmanesh M (2009) The relationship of body mass index and blood pressure in Iranian children $<7$ years old. $J$ Trop Pediatr 55, 313-317.

23. He Q, Ding ZY, Fong DY, et al. (2000) Blood pressure is associated with body mass index in both normal and obese children. Hypertension 36, 165-170.

24. Raj M, Sundaram KR, Paul M, et al. (2010) Body mass index trend and its association with blood pressure distribution in children. J Hum Hypertens 24, 652-658.

25. Wang Z, Ma J, Dong B, et al. (2011) Comparison of blood pressure levels among four age groups of Chinese children matched by height. J Hum Hypertens (Epublication ahead of print version 12 May 2011).

26. Paradis G, Lambert M, O'Loughlin J, et al. (2004) Blood pressure and adiposity in children and adolescents. Circulation 110, 1832-1838.

27. Maximova K, O'Loughlin J, Paradis G, et al. (2010) Changes in anthropometric characteristics and blood pressure during adolescence. Epidemiology 21, 324-331.

28. Ying-Xiu Z \& Shu-Rong W (2010) Distribution of skinfold thickness and blood pressure among children and adolescents in Shandong. China. J Trop Pediatr 57, 258-262.

29. Ma J, Wang Z, Dong B, et al. (2011) Quantifying the relationships of blood pressure with weight, height and body mass index in Chinese children and adolescents. J Paediatr Child Health (Epublication ahead of print version 3 November 2011).

30. Daniels SR, Kimball TR, Khoury P, et al. (1996) Correlates of the hemodynamic determinants of blood pressure. Hypertension 28, 37-41.

31. Julius S, Majahalme S, Nesbitt S, et al. (2002) A "gender blind" relationship of lean body mass and blood pressure in the Tecumseh study. Am J Hypertens 15, 258-263.

32. Wajchenberg BL (2000) Subcutaneous and visceral adipose tissue: their relation to the metabolic syndrome. Endocr Rev 21, 697-738. 